\title{
Awareness of working women in Mansoura University about ovarian cancer: An intervention follow-up study
}

\author{
Hanan El-Sayed Mohamed *1, Rabab Gad Abd Elkader ${ }^{2}$ \\ ${ }^{1}$ Woman's Health and Midwifery Nursing, Mansoura University, Mansoura, Egypt \\ ${ }^{2}$ Community Health Nursing, Mansoura University, Mansoura, Egypt
}

Received: July 12, 2015

DOI: $10.5430 /$ jnep.v6n2p10
Accepted: October 12, $2015 \quad$ Online Published: October 25, 2015

URL: http://dx.doi.org/10.5430/jnep.v6n2p10

\begin{abstract}
Background and Aim: Ovarian cancer causes more death than any other gynecologic tumor, other than it accounts for about $3 \%$ of all cancers in women. Aim: This study was aimed to raise the awareness of working women in Mansoura University about ovarian cancer.

Methods: Study Design: A quasi-experimental one group pre-post test design was utilized. Setting: The study was conducted in different faculties of Mansoura University. Subjects: The study subjects included 199 working women in different faculties of Mansoura University distributed as: 92 women from practical faculties, 33 from theoretical faculties and 74 from medical faculties using a stratified random sample. Tool: Self-administered questionnaire consists of three different parts. The first part includes socio-demographic characteristics of working women, the second part includes the source of knowledge about ovarian cancer and the third part includes the working women knowledge about ovarian cancer.

Results: About $46.7 \%$ of the study sample their age ranged from 35 to less than 50 years. About $41.2 \%$ among the study group did not have any source of knowledge about ovarian cancer. The study participants had poor knowledge about the ovarian cancer manifestation, risk factor, treatment and prevention in the pre test that improved after the educational session.

Conclusions: The health education session about ovarian cancer showed a significant effect in the form of a remarkable increase in the participants' level of knowledge about the disease. Thus, health education about ovarian cancer should be adopted as an element of the services offered to the working women.
\end{abstract}

Key Words: Ovarian cancer, Awareness, Knowledge, An intervention follow up study

\section{INTRODUCTION}

Cancer is the most significant worldwide health problem with wide geographical variation in incidence and it is also becoming an important item in every country's health agenda. Cancer is the unlimited growth and spread of cells, the growth most often invades surrounding tissue and can metastasize to distant sites. It can affect any part of the body. ${ }^{[1]}$

Ovarian cancer causes more deaths than any other cancer of the female reproductive system, but it accounts for only about $3 \%$ of all cancers in women. The worldwide incidence of ovarian cancer is 238,700 new cases per year, with a global mortality of 151,900 deaths per year. ${ }^{[2]}$

U.S. Department of Health and Human Services Statistics ${ }^{[3]}$ showed that, among women in the United States, ovarian cancer is the eighth most common cancer and the fifth leading cause of cancer death. Each year, about 22,000 women

\footnotetext{
*Correspondence: Hanan El-Sayed Mohamed; Email: alemam2100@yahoo.com; Address: Woman’s Health and Midwifery Nursing, Mansoura University, Mansoura, Egypt.
} 
in the United States get ovarian cancer and approximately 14,000 died from the disease.

In Egypt, the incidence rate of ovarian cancer during the period from 2008 to 2011 in Lower Egypt (5.1), Middle Egypt (3.6), and Upper Egypt (7.1)/100,000 populations. The estimated number of ovarian cancer cases in 2015 will be $2,434 .{ }^{[4]}$

In spite of the fact that ovarian cancer is, the common form of gynecological cancer, it remains difficult to diagnose ${ }^{[5]}$ because symptoms are easily becoming confused with other illnesses. Signs and symptoms of ovarian cancer are very often absent early on and when they occur they may be shrewd. In most conditions the symptoms keep for several months before being recognized and diagnosed in late stage, but when ovarian cancer is found in its early stages, treatment is most effective. ${ }^{[6]}$

There are many risk factors of ovarian cancer as it increases with age and high incidence rate in women in their late 70 s. $^{[7]}$ Also, women who have breast cancer or have a family history of breast or ovarian cancer that demonstrates only $5 \%$ to $15 \%$ of cases of ovarian cancer. Woman without children, no breastfeeding, and hormonal replacement therapy are associated risk factors. Despite the fact that some of the risk factors that increase the woman's chance to develop ovarian cancer are relatively familiar the real cause of cancer is not known. ${ }^{[8,9]}$

Early detection improves a woman's chance of ovarian cancer treatment, but an early diagnosis of ovarian cancer is difficult and up to date there are no standardized screening programs. ${ }^{[10]}$ Although there is not a definitive diagnostic tool at this time, there is enough information regarding the associated signs and symptoms, risk and protective factors of ovarian cancer so educating women could help to reduce the delay in diagnosis time, and associated rates of morbidity and mortality. ${ }^{[11]}$

Research confirms that the majorities of women with ovarian cancer is symptomatic and frequently have delays in diagnosis. ${ }^{[12]}$ Goff et al. $^{[12]}$ reported that, if women were educated about the signs and symptoms of ovarian cancer, patient-related delays in diagnosis could have an impact on a woman's survival rate. Indeed, the Health Belief Model (HBM), corroborates that, if women were aware of the signs, symptoms and risk factors of ovarian cancer, they might be more likely to seek medical care early if they developed symptoms of ovarian cancer. ${ }^{[13]}$

\subsection{Significance of the study}

About $85 \%$ of women were not aware about the symptoms of ovarian cancer, $80.6 \%$ never talked with their physicians about the symptoms of ovarian cancer and $65 \%$ of them incorrectly identified that Pap test is efficient in detecting ovarian cancer. ${ }^{[14]}$ Health education is the most excessively adopted health promotion strategies used with young people, and is nearly universally represented as effective. There is evidence that in most developed countries the integration of professional and public education help to decrease the size of cancers. ${ }^{[15]}$ It provides people with more knowledge and enabling them to be responsible for and protect their own health. ${ }^{[16]}$ So it is important to educate women about the symptoms of ovarian cancer, risk factors, and preventive measures.

In Egypt until now, there have been no published studies to raise the awareness of the working women about ovarian cancer, including signs and symptoms in addition to risk factors and prevention. Therefore, the purpose of this study was to raise the awareness of working women in Mansoura University about ovarian cancer.

\subsection{Aim of the study}

The aim of this study was to raise the awareness of working women in Mansoura University about ovarian cancer.

\subsection{Research hypothesis}

The awareness of working women in Mansoura University about ovarian cancer will improve based on the health education session.

\section{SUBJECTS AND METHOD}

\subsection{Research design}

A quasi-experimental design - one group pre-post test.

\subsection{Study setting}

This study was conducted at the faculties of Mansoura University, Egypt, from July to September 2014.

\subsection{Subjects of the study}

The study subjects were included 199 working women in different faculties of Mansoura University distributed as: 92 women from practical faculties, 33 from theoretical and 74 from medical faculties using stratified random sample adopting the systematic approach, where the first name was selected by the blind method and then followed by selection of each third name from the lists of the working women. Women who had already participated in other health education sessions related to ovarian cancer were excluded from the study. And do not have ovarian cancer. Sample size was calculated online: (https://www.dssresearch.com/knowledgecenter/ toolkitcalculators/samplesizecalculators.asp) 
with the following assumption: $3 \%$ precision, $5 \%$ alpha error and $20 \%$ Beta error ( $80 \%$ study power), then sample size $=$ 181. We added $10 \%$ to compensate for drop outs. Thus final sample $=199$ working women .

\subsection{Tool of data collection}

Structured Self-administered questionnaire was developed in Arabic language by the researchers after reviewing the related literatures. It consists of three parts: Part I: This part included questions related to socio-demographic characteristics of working women such as age, faculty, education level, marital status and residence. Part II: This part consisted of items related to source of knowledge about ovarian cancer such as media (TV, radio, newspaper), medical staff, relatives and friends. Part III: This part entailed items related to the knowledge of working women about ovarian cancer as definition, risk factors e.g., family history, age of menarche and menopause, signs and symptoms as pain, eating problem, abdominal problems, bowels, bladder manifestation, diagnostic test, management and prevention.

Scoring of the items: Each correct answer was given a score equal " 2 ", the wrong answer was given a score equal " 1 " and don't know the answer was given a score equal "zero". Maximum knowledge score of the working women was equal (94).

Scoring key for the knowledge regarding ovarian cancer:

- Poor knowledge $0-<50 \%$, Score $0-<46$;

- Fair knowledge 50\%-<75\%, Score 47-<70;

- Good knowledge 75\%-<100\%, Score 70-94.

Validity of the tool: Validity of this tool was tested by five experts; two experts in maternity nursing, one expert in obstetric medicine and two experts in community health nursing.

Development of health education session: The health education session about ovarian cancer was prepared based on the review of literature. Colored booklet was prepared according to the content in simple Arabic language. The developed content was given to five experts to establish the content validity and they were requested to give their opinion and suggestions about the content of the session. According to expert's suggestions the content was modified.

\subsection{Ethical considerations}

Written consent was obtained from the study participants. They were reassured about the confidentiality of the information. They were informed about their rights to refuse participation or withdraw at any time.

\subsection{Pilot study}

A pilot study was conducted for 20 of the working women (about $10 \%$ of the sample size) in order to test the applicability and relevance of the study tools and to test the clarity of the designed questionnaire as well as to calculate the sample size. The necessary modifications were done and these women were excluded from the study sample.

\subsection{Field work}

- At first an official letter was issued to the administrator of the different faculties of Mansoura University.

- The study was conducted from the beginning of July to September 2014 among women worked in different faculties of Mansoura University.

- Prior to data collection the researcher introduced herself and explained the purpose of the study.

- About 14 groups were used for intervention in all faculties, each faculty group of working women was divided into subgroups, and each group consisted of 10-15 participants and it takes one teaching session.

- A pre test was conducted as a first level of intervention by distributing the structured questionnaire after adequate explanation for the subjects in each group.

- Each faculty group took 20-25 minutes to complete the questionnaire, after that one teaching session 3hour interactive lecture were used, using power point presentation, followed by a group discussion. The content was included information about the definition of ovarian cancer, signs and symptoms, causes, risk factors, prevention, treatment and at the end of lecture colored Arabic booklet of ovarian cancer was given to the participants that was prepared by the researchers.

- The post test was done immediately after administration of the educational session by using the same questionnaire

- Follow up was done after three months of administration of a session using the same questionnaire. The number of dropouts was 17 working women.

\subsection{Statistical analysis}

Statistical Package for Social Sciences (SPSS) version 16.0 was used for the statistical analysis of the obtained data. Data were presented using descriptive statistics in the form of frequencies, percentages, means and standard deviations for quantitative variables. Correlation $(r)$ test and qui-square test were used. Statistical significance was considered at $p$-value $<.05$, a highly significant difference obtained at $p<.01$ and non significant difference obtained at $p>.05$. 


\section{RESUlts}

Table 1 clarifies the general characteristics of the study group in which their mean age was $39.76 \pm 1.07$ years. More than one-third $(37.7 \%)$ of them were university graduate while $(32.7 \%)$ had intermediate (2 years) institute education. More than two third of women $(69.8 \%)$ were married, and more than half of them $(57.8 \%)$ from urban residential.

Table 1. Distribution of the study group according to their socio-demographic characteristics

\begin{tabular}{lll}
\hline General characteristics & Frequency & \% \\
\hline Age (by years) & 72 & 36.2 \\
$20-<35$ & 93 & 46.7 \\
$35-50$ & 34 & 17.1 \\
$>50$ & $39.76 \pm 1.07$ & \\
Mean \pm SD & & \\
Faculty type & 33 & 16.6 \\
Theoretical & 74 & 37.2 \\
Medical & 92 & 46.2 \\
Practical & & \\
Education level & 45 & 22.6 \\
Secondary & 65 & 32.7 \\
Intermediate (2 years) institute & 75 & 37.7 \\
University graduate & 14 & 7.0 \\
Postgraduate degree & & \\
Marital status & 139 & 69.8 \\
Married & 36 & 18.1 \\
Single & 6 & 3.0 \\
Divorced & 18 & 9.1 \\
Widowed & & \\
Residence & 84 & 57.8 \\
Rural & 115 & \\
Urban & & \\
\hline & & \\
\hline
\end{tabular}

As regards source of information Figure 1 displays that, more than one third $(41.2 \%)$ of the study group did not hear about ovarian cancer. TV, radio, and newspaper as media source represented (27.1\%). Health education through medical staff represented $(17.1 \%)$. Those who mentioned relatives $\&$ friends as a source of information represented $(14.6 \%)$ which is the least one.

Table 2 shows that, there was improvement in the study group's knowledge about ovarian cancer, risk and protective factors in pre intervention compared to post intervention and follow up tests. As regards the family history as risk factors the correct answer of the women improved from pretest $(32.2 \%)$ to $(87.9 \%)$ post test. On the other hand, use of oral contraceptives and breastfeeding as a protective factor reported by the women in the pretest $(31.7 \%, 10.6 \%)$ respectively; and it was more improved in post test $(66.8 \%, 52.8 \%)$ respectively, compared to follow up test $(72.0 \%, 77.5 \%)$ respectively. Regarding the surgical removal of the uterus or ovaries, the correct answer in the pre test was (10.1\%) and improved in the post and follow up tests $(71.4 \%, 72.0 \%)$ correspondingly.

Table 3 reveals that, only (17.6\%), (17.6\%), (14.1\%), $(10.1 \%)$, and $(16.6 \%)$ of the studied women had a good knowledge score about the pain, bladder, general manifestation, intercourse, bowels, and menstrual manifestations of the ovarian cancer in that order respectively. After the health education session, a remarkable improvement of the women knowledge score $(82.4 \%),(72.4 \%),(81.9 \%),(62.3 \%)$, and (76.9\%) was observed in comparison to pre-intervention. Regarding the results of the follow up test the frequency of improvement was declined.

Concerning knowledge score of the working women, findings in Table 4 illustrates that, more than half $(58.8 \%)$ of women had good knowledge about the definition, while only $14.6 \%, 13.6 \%, 3.0 \%$ of them had good knowledge about manifestation, treatment, risk factors and prevention before the intervention respectively. After intervention, a remarkable improvement in working women's level of knowledge $(97.0 \%)$ in definition, (88.4\%) manifestation, and $(71.9 \%)$ risk factor, treatment $(57.1 \%)$ and prevention $(67.3 \%)$. Regarding the results of the follow up the improvement was declined.

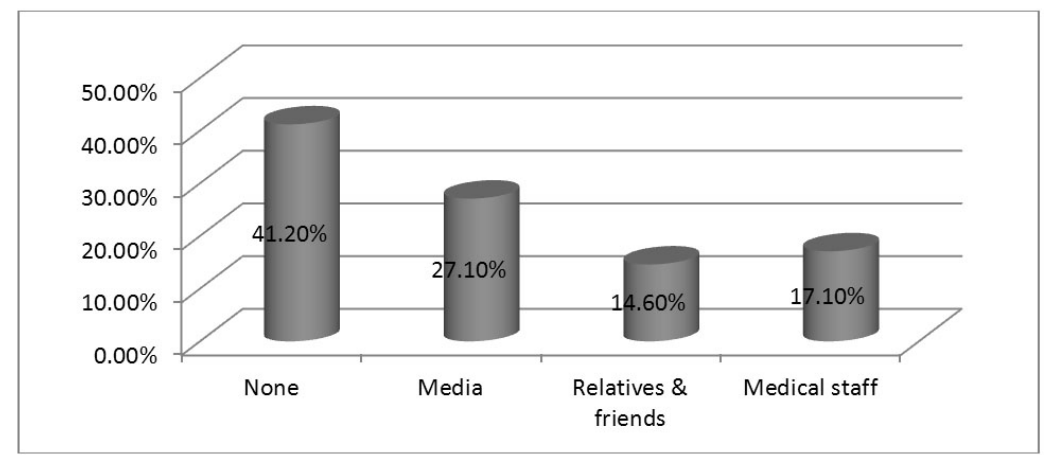

Figure 1. Percentage distribution of the study group according to source of information about ovarian cancer 
Table 2. Distribution of the study group according to their correct knowledge about risk and protective factors of ovarian cancer

\begin{tabular}{|c|c|c|c|c|c|c|}
\hline \multirow{2}{*}{ Item } & \multicolumn{2}{|c|}{ Pre $(n=199)$} & \multicolumn{2}{|c|}{ Post $(n=199)$} & \multicolumn{2}{|c|}{ Follow up $(n=182)$} \\
\hline & No. & $\%$ & No. & $\%$ & No. & $\%$ \\
\hline \multicolumn{7}{|l|}{ Risk factors } \\
\hline -Family history & 64 & 32.2 & 175 & 87.9 & 125 & 68.7 \\
\hline -Genetic factor & 82 & 41.2 & 184 & 92.5 & 138 & 75.8 \\
\hline -Age & 64 & 32.2 & 154 & 77.4 & 130 & 71.4 \\
\hline -Infertility & 48 & 24.1 & 133 & 66.8 & 142 & 78.0 \\
\hline -X-ray exposure & 32 & 16.1 & 151 & 75.9 & 128 & 70.3 \\
\hline -Early age of menarche & 15 & 7.5 & 110 & 55.3 & 138 & 75.8 \\
\hline -Early age of menopause & 21 & 10.6 & 117 & 58.8 & 137 & 75.3 \\
\hline \multicolumn{7}{|l|}{ Protective factors } \\
\hline -Use of oral contraceptive & 63 & 31.7 & 133 & 66.8 & 131 & 72.0 \\
\hline -Breastfeeding & 21 & 10.6 & 105 & 52.8 & 141 & 77.5 \\
\hline -Use of hormonal therapy & 57 & 28.6 & 127 & 63.8 & 143 & 78.6 \\
\hline -Surgical removal of uterus or ovaries & 20 & 10.1 & 142 & 71.4 & 131 & 72.0 \\
\hline
\end{tabular}

Table 3. Distribution of the study group according their knowledge score about the manifestation of ovarian cancer

\begin{tabular}{|c|c|c|c|c|c|c|c|c|c|}
\hline \multirow[b]{2}{*}{ Manifestations } & \multicolumn{3}{|c|}{ Pre $(n=199)$} & \multicolumn{3}{|c|}{ Post $(n=199)$} & \multicolumn{3}{|c|}{ Follow up $(n=182)$} \\
\hline & $\begin{array}{l}\text { Poor } \\
\text { No. } \\
\%\end{array}$ & $\begin{array}{l}\text { Fair } \\
\text { No. } \\
\%\end{array}$ & $\begin{array}{l}\text { Good } \\
\text { No. } \\
\%\end{array}$ & $\begin{array}{l}\text { Poor } \\
\text { No. } \\
\%\end{array}$ & $\begin{array}{l}\text { Fair } \\
\text { No. } \\
\%\end{array}$ & $\begin{array}{l}\text { Good } \\
\text { No. } \\
\%\end{array}$ & $\begin{array}{l}\text { Poor } \\
\text { No. } \\
\%\end{array}$ & $\begin{array}{l}\text { Fair } \\
\text { No. } \\
\%\end{array}$ & $\begin{array}{l}\text { Good } \\
\text { No. } \\
\%\end{array}$ \\
\hline \multirow{2}{*}{ Pain } & 137 & 27 & 35 & 13 & 22 & 164 & 26 & 29 & 127 \\
\hline & 68.8 & 13.6 & 17.6 & 6.5 & 11.1 & 82.4 & 14.3 & 15.9 & 69.8 \\
\hline \multirow{2}{*}{ Abdominal } & 104 & 41 & 54 & 9 & 15 & 175 & 8.0 & 40 & 134 \\
\hline & 52.3 & 20.6 & 27.1 & 4.5 & 7.5 & 87.9 & 4.4 & 22.0 & 73.6 \\
\hline \multirow{2}{*}{ Menstrual } & 122 & 44 & 33 & 9.0 & 37 & 153 & 12 & 63 & 107 \\
\hline & 61.3 & 22.1 & 16.6 & 4.5 & 18.6 & 76.9 & 6.6 & 34.6 & 58.8 \\
\hline \multirow{2}{*}{ General } & 134 & 37 & 28 & 6.0 & 30 & 163 & 11 & 62 & 109 \\
\hline & 67.3 & 18.6 & 14.1 & 3.0 & 15.1 & 81.9 & 6.0 & 34.1 & 59.9 \\
\hline \multirow{2}{*}{ Eating problems } & 123 & 20 & 56 & 3.0 & 12 & 184 & 18 & 20 & 144 \\
\hline & 61.8 & 10.1 & 28.1 & 1.5 & 6.0 & 92.5 & 9.9 & 11.0 & 79.1 \\
\hline \multirow{2}{*}{ Bowels } & 112 & 67 & 20 & 5.0 & 70 & 124 & 4.0 & 132 & 46 \\
\hline & 56.3 & 33.7 & 10.1 & 2.5 & 35.2 & 62.3 & 2.2 & 72.5 & 25.3 \\
\hline \multirow{2}{*}{ Bladder } & 103 & 61 & 35 & 1.0 & 54 & 144 & 3.0 & 102 & 77 \\
\hline & 51.8 & 30.7 & 17.6 & 0.5 & 27.1 & 72.4 & 1.6 & 56.0 & 42.3 \\
\hline \multirow{2}{*}{ Intercourse } & 116 & 54 & 29 & 9.0 & 58 & 132 & 3.0 & 79 & 100 \\
\hline & 58.3 & 27.1 & 14.6 & 4.5 & 29.1 & 66.3 & 1.6 & 43.4 & 54.9 \\
\hline
\end{tabular}

Concerning the knowledge level of the study group Figure 2 illustrates that, only (6.5\%) of women had good knowledge about ovarian cancer during pre-test. After intervention, the majority of them (81.4\%) had good knowledge. Regarding the results of the follow up the improvement was decreased to $(76.9 \%)$. There was a highly statistically significant difference $(p=.000)$ between the knowledge score of the study group pre, post and follow up.

Regarding the relation between socio-demographic characteristics and knowledge score, Table 5 shows that, the working women aged from 35 to $>50$ years had the highest percentage 14
(34.2\%) of poor knowledge pre intervention. Also the working women in the urban area around half (49.2\%) of them had poor knowledge. Regarding education, more than quarter (27.6\%) of university graduate women had poor knowledge. Post intervention the knowledge improved (37.2\%) of working women aged from 35 to $>50$ years, also $(48.8 \%)$ among women in urban residence, and (29.6\%) of the university graduate women. There is a highly statistically significant difference between the rural and urban knowledge in pre intervention study. And also, in the pre-intervention, there is a highly statistically significant difference between educational level and knowledge score. 
Table 4. Distribution of the study group according to their knowledge score about ovarian cancer $(\mathrm{n}=199)$

\begin{tabular}{|c|c|c|c|c|c|c|c|c|c|}
\hline \multirow[b]{2}{*}{ Item } & \multicolumn{3}{|c|}{ Pre $(n=199)$} & \multicolumn{3}{|c|}{ Post $(n=199)$} & \multicolumn{3}{|c|}{ Follow up $(n=182)$} \\
\hline & $\begin{array}{l}\text { Poor } \\
\text { No. } \\
\%\end{array}$ & $\begin{array}{l}\text { Fair } \\
\text { No. } \\
\%\end{array}$ & $\begin{array}{l}\text { Good } \\
\text { No. } \\
\%\end{array}$ & $\begin{array}{l}\text { Poor } \\
\text { No. } \\
\%\end{array}$ & $\begin{array}{l}\text { Fair } \\
\text { No. } \\
\%\end{array}$ & $\begin{array}{l}\text { Good } \\
\text { No. } \\
\%\end{array}$ & $\begin{array}{l}\text { Poor } \\
\text { No. } \\
\%\end{array}$ & $\begin{array}{l}\text { Fair } \\
\text { No. } \\
\%\end{array}$ & $\begin{array}{l}\text { Good } \\
\text { No. } \\
\%\end{array}$ \\
\hline \multirow{2}{*}{ Definition } & 68 & 14 & 117 & 6 & 0 & 193 & 4 & 24 & 154 \\
\hline & 34.2 & 7.0 & 58.8 & 3.0 & .0 & 97.0 & 2.2 & 13.2 & 84.6 \\
\hline \multirow{2}{*}{ Manifestation } & 136 & 34 & 29 & 3 & 20 & 176 & 31 & 13 & 138 \\
\hline & 68.3 & 17.1 & 14.6 & 1.5 & 10.1 & 88.4 & 17.0 & 7.1 & 75.8 \\
\hline \multirow{2}{*}{ Risk factor } & 146 & 26 & 27 & 14 & 42 & 143 & 2 & 34 & 146 \\
\hline & 73.4 & 13.1 & 13.6 & 7.0 & 21.1 & 71.9 & 1.1 & 18.7 & 80.2 \\
\hline \multirow{2}{*}{ Treatment } & 141 & 29 & 29 & 49 & 36 & 113 & 40 & 100 & 42 \\
\hline & 70.9 & 14.6 & 14.6 & 24.7 & 18.2 & 57.1 & 22.0 & 54.9 & 23.1 \\
\hline \multirow{2}{*}{ Prevention } & 191 & 2.0 & 6 & 52 & 13 & 134 & 28 & 16 & 138 \\
\hline & 96.0 & 1.0 & 3.0 & 26.1 & 6.5 & 67.3 & 15.4 & 8.8 & 75.9 \\
\hline
\end{tabular}

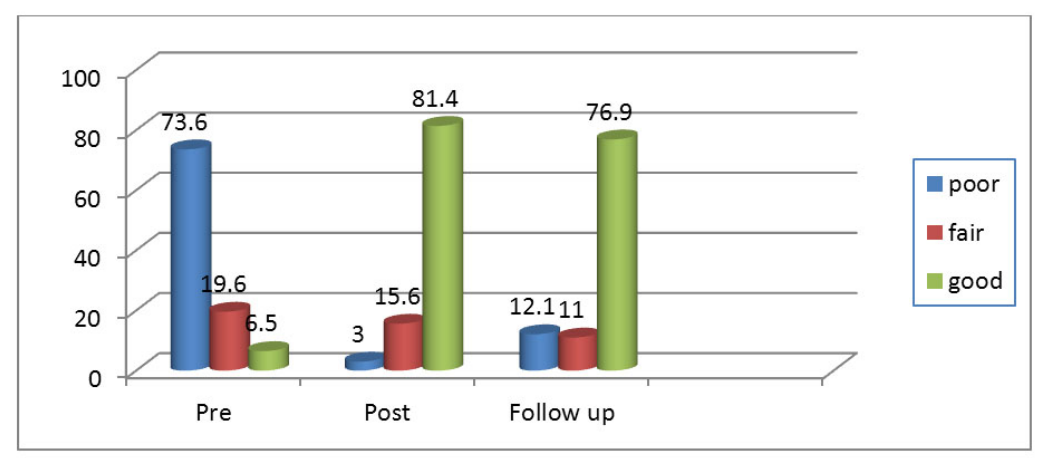

Figure 2. Total knowledge score of the study group about ovarian cancer

Table 5. Relation between socio-demographic data and knowledge score of the study group

\begin{tabular}{|c|c|c|c|c|c|c|c|c|c|}
\hline \multirow{3}{*}{ Item } & \multicolumn{3}{|c|}{ Pre $(n=199)$} & \multicolumn{3}{|c|}{ Post $(n=199)$} & \multicolumn{3}{|c|}{ Follow up $(\mathrm{n}=182)$} \\
\hline & Poor & Fair & Good & Poor & Fair & Good & Poor & Fair & Good \\
\hline & $\%$ & $\%$ & $\%$ & $\%$ & $\%$ & $\%$ & $\%$ & $\%$ & $\%$ \\
\hline \multicolumn{10}{|l|}{ Age } \\
\hline $20->35$ & 25.6 & 9.1 & 1.5 & 1.1 & 5.03 & 30.2 & 3.3 & 3.5 & 30.8 \\
\hline $35->50$ & 34.2 & 8.0 & 4.5 & 1.1 & 8.5 & 37.2 & 7.7 & 5.5 & 31.3 \\
\hline $50-$ & 14.1 & 2.5 & 0.5 & 1.1 & 2.01 & 14.1 & 1.1 & 1.6 & 14.8 \\
\hline Chi-square & 488.4 & & & 213.1 & & & 446.9 & & \\
\hline$P$-value & $>.05$ & & & $>.05$ & & & $>.05$ & & \\
\hline \multicolumn{10}{|l|}{ Residence } \\
\hline Rural & 24.6 & 13.6 & 4.0 & 2.5 & 7.0 & 32.7 & 5.5 & 3.8 & 32.9 \\
\hline Urban & 49.2 & 6.1 & 2.5 & 0.5 & 8.5 & 48.8 & 6.6 & 7.1 & 44 \\
\hline Chi-square & 1841.3 & & & 455.9 & & & 54.4 & & \\
\hline$P$-value & $.000^{*}$ & & & $>.05$ & & & $>.05$ & & \\
\hline \multicolumn{10}{|l|}{ Education } \\
\hline Secondary & 21.1 & 1.1 & 0.5 & 1.5 & 3.01 & 18.1 & 1.6 & 2.2 & 19.8 \\
\hline Institute & 18.6 & 8.5 & 0.5 & 0.5 & 4.02 & 28.1 & 4.4 & 4.4 & 23.6 \\
\hline University & 27.6 & 10.1 & 0.5 & 1.1 & 7.04 & 29.6 & 4.9 & 3.3 & 29.1 \\
\hline Postgraduate & 6.5 & 0.0 & 0.5 & 0.0 & 1.5 & 5.5 & 1.1 & 1.1 & 4.4 \\
\hline Chi-square & 3380.5 & & & 454.5 & & & 298.2 & & \\
\hline$P$-value & $.000^{*}$ & & & $>.05$ & & & $>.05$ & & \\
\hline
\end{tabular}

* Highly statistical significance $p<.01$ 


\section{Discussion}

Prevention is better than cure; any educational intervention mainly focuses on increase the participant's awareness about the problem for early detection, treatment and prevention of further complications. The present study was aimed to raise the awareness of working women in Mansoura University about ovarian cancer through educational session.

As regards to the women's level of knowledge, the majority of them had poor information about the disease before health education. This is may be due to shortage of educational messages in the mass media about ovarian cancer as well as poor awareness related to the value of health. Post intervention the majority of the women had good knowledge. This is may be due to clarity and simple language of the session, the proper method of teaching and educational materials used. Also the women's readiness to promote and maintain a healthy lifestyle was involved and to know about the disease did not hear about it before. This was in consistency Glanz et al. ${ }^{[13]}$ who describes knowledge of working women in Malaysia general public regarding ovarian cancer and reported that overall knowledge of Malaysian working women was very poor.

In relation to the women's knowledge about symptoms that considered as a screening tool because there are no ovarian cancer screening tools with sufficient accuracy to be recommended for use in the general population. The findings of the current study showed that more than half of women had poor knowledge pre intervention about manifestation including pain, abdominal manifestation, changes in the bowels and bladder, menstrual and intercourse symptoms. This was in agreement with Goff et al. ${ }^{[12]}$ who assess women's awareness of ovarian cancer risks and symptoms and showed that women were not knowledgeable about symptoms associated with ovarian cancer.

In addition, the present study findings were incongruent with Al-Naggar et al $^{[17]}$ who reported that the participants had poor knowledge about symptoms of ovarian cancer. Also, these results were in the same line with Brain et al. ${ }^{[18]}$ who study ovarian cancer symptom awareness and reported that many ovarian symptoms were not well recognized by women in the sample.

Moreover, Low et al. ${ }^{[19]}$ who was studied ovarian cancer symptoms awareness and anticipated time to help-seeking for symptoms among UK women and found that awareness of ovarian cancer symptoms was low in the UK. After educational session, findings showed almost of the participant had good level of knowledge. This is may be due to simple media of education used which in turn increased the women self awareness about the value of health.
Concerning the women's knowledge about the risk factors, the majority of the women had poor knowledge about risk factors pre-educational session as age, family history, and genetic factors. This is could be due to lack of information resources and programs regard risk factors of ovarian cancer. The current study findings were in agreement with Glanz et $a l .{ }^{[13]}$ who reported that, the study subjects showed a poor knowledge about risk factors. Also the present study results were in agreement with Goff et al. ${ }^{[12]}$ who reported that, women were not knowledgeable about risk factors associated with ovarian cancer. After educational session, findings showed significant increase in the participant level of knowledge due to the effect of the session.

Regarding women's knowledge about the protective factors needed to prevent ovarian cancer as the use of oral contraceptive, breastfeeding, surgical removal of the uterus and ovaries. Study findings revealed that the majority of women had poor information regarding protective factors before the educational session. This could be due to lack of information resources as mass media about protective factors and prevention of ovarian cancer. These results were in the same line with American cancer society ${ }^{[20]}$ who reported that, using oral contraceptives were decreasing the risk of developing ovarian cancer, especially among women who were used them for several years. Also, tubal ligation and hysterectomy may reduce the chance of developing ovarian cancer.

In additional to Tworoger et al. ${ }^{[21]}$ that studied the relation of infertility, oral contraceptive use, and other contraceptive methods with cancer risk factors and reported that reproductive factors that interrupt ovulation, such as oral contraceptive use, pregnancy and lactation had relation with decreased ovarian cancer risk factors. Also the present study results were in consistency with Rice et al. ${ }^{[22]}$ who studied the association between hysterectomy, gynecologic surgeries, tubal ligation and ovarian cancer and reported that hysterectomy and tubal ligation were associated with a reduced the risk of ovarian cancer, by approximately $26-30$. There were no researches done to assess the knowledge of working women about the protective factors of ovarian cancer.

After the educational session the majority of women had information about preventive factors for ovarian cancer. This could be due to the clarity and consistency of the educational session and proper media used.

Regarding the source of knowledge the present study results showed that less than half of women did not have any source of knowledge about ovarian cancer. This was in agreement with ${ }^{[13]}$ who reported that media focus very much on breast and cervical cancer not ovarian cancer, such as advertisements in TV, radio, magazines and newspapers. 
There was a highly statistically significant improvement in the total score level of knowledge of the working women about ovarian cancer (definition, manifestation, risk factor, treatment and prevention) post-educational session and in follow up in comparison to pre-educational session results. These results emphasized the readiness of the working women to gain more information about the diseases that harm health.

The results of the present study showed that, the educational session was effective in improving the participants' knowledge as reflected in both post and follow up scores. These findings supported the study hypothesis that health education session for working women will improve their level of knowledge about ovarian cancer.

\section{Limitation of the study}

During implementation of educational sessions the majority of the subjects were punctual because all of them were selected from different departments. Hence, most of teaching sessions were done for small groups (10-15 participants) that consumed much time and efforts from the researchers to cover the whole sample.

\section{Conclusion}

The majority of the study group had poor information about ovarian cancer manifestation, risk factors as well as preventive procedures. The developed health educational session showed a significant effect in a remarkable increase of the participants level of knowledge about ovarian cancer.

\section{Recommendation}

- Health education about ovarian cancer should be adopted as an element of the services offered to the working women.

- Channels of mass media should be utilized to disseminate the information about the prevention of ovarian cancer and women health.

- Health education campaign in rural and urban area to raise the awareness of all women about ovarian cancer.

\section{ACKNOWLEDGements}

We are extremely grateful to all participants of this research.

\section{CONFliCtS OF INTEREST Disclosure}

The authors declare that there is no conflict of interest.

\section{REFERENCES}

[1] World Health Organization. World Cancer Day 2015, organized by the Union for International Cancer Control, is an opportunity to highlight the wide range of actions. 2015.

[2] International Agency for Research on Cancer. Estimated cancer incidence, mortality and prevalence worldwide. 2012.

[3] U.S. Department of Health and Human Services. U.S. Cancer Statistics Working Group. United States Cancer Statistics: 1999-2011. Incidence and Mortality Web-based Report. Atlanta (GA): Centers for Disease Control and Prevention, and National Cancer Institute. 2014.

[4] Ibrahim A, Khaled H, MikhailN, et al. Cancer Incidence in Egypt: Results of the National Population-Based Cancer Registry Program. Journal of Cancer Epidemiology. 2014. PMid:25328522 http: //dx.doi.org/10.1155/2014/437971

[5] Ovary Cancer Resource Center, Ovary cancer. American Cancer Society. 2001.

[6] Piek JM, Van Diest PJ, Verheijen RH. Ovarian carcinogenesis: an alternative hypothesis. The advances in Experimental Medicine and Biology Journal. 2008; 622: 79-87. PMid:18546620 http: //dx.doi.org/10.1007/978-0-387-68969-2_7

[7] Russo A, Calò V, Bruno L, et al. Hereditary ovarian cancer. Crit Rev OncolHematol Journal. 2009; 69(1): 28-44. PMid:18656380 http://dx.doi.org/10.1016/j.critrevonc.2008.06.003

[8] Prat J. Ovarian carcinomas: five distinct diseases with different origins, genetic alterations, and clinicopathological features. Virchows Arch Journal. 2012; 460: 237-249. PMid:22322322 http: //dx.doi.org/10.1007/s00428-012-1203-5

[9] South SA, Vance H, Farrell C, et al. Consideration of hereditary nonpolyposis colorectal cancer in BRCA mutation-negative familial ovariancancers. Cancer Journal. 2009; 115(2): 324-33. PMid:19117025 http://dx.doi .org/10.1002/cncr. 24012

[10] Sato S, Yokoyama Y, Sakamoto, et al. Usefulness of mass screenings for ovarian carcinoma using trans-vaginal ultrasonography. Cancer Journal. 2000; 89(3): 582-588. http://dx. doi .org/10.1002/1 097-0142(20000801)89:3<582: : AID-CNCR13>3.0.C0;2-\#

[11] Bradbury J. Ovarian cancer not so silent after all. LANCET. 2000; 356(9244): 1826. http://dx.doi.org/10.1016/S0140 $-6736(05) 73293-1$

[12] Goff BA, Mandel LS, Muntz G, et al. Ovarian cancer diagnosis; results of a national ovarian cancer survey. University of Washington, Seattle, Virginia Mason Med Ctr. Seattle, WA. 2000.

[13] Glanz K, Lewis FM, Rimer BK. Health Behavior and Health Education. San Francisco, Ca.: Jossey-Bass; 1997.

[14] Rayermann S, Donovan H, Rambo D, et al. Women's awareness of ovarian cancer risks and symptoms. American Journal of Nursing. 2009; 109(9): 36-45. PMid:19704232 http://dx.doi.org/10. 1097/01.NAJ .0000360309.08701.73

[15] Miller W, Rollnick S. Ten things that motivational interviewing is not behavioural and cognitive. Psychotherapy Journal. 2009; 37: 129-149.

[16] Price N, Knibbs S. How effective is peer education in addressing young people's sexual and reproductive health needs in developing countries? Children \& Society Journal. 2009; 23(4): 291-302. http://dx.doi.org/10.1111/j.1099-0860.2008.00175.x

[17] Al-Naggar RA, Osman MT, Bobryshev YV, et al. Ovarian Cancer: Knowledge of Risk Factors and Symptoms among Working Malaysian Women. Middle-East Journal of Scientific Research. 2013; 14 (4): 549-553.

Published by Sciedu Press 
[18] Brain KE, Smits S, Simon A, et al. Ovarian cancer symptom awareness and anticipated delayed presentation in a population sample. BMC Cancer Journal. 2014; 14: 171. PMid:24612526 http://dx.doi.org/10.1186/1471-2407-14-171

[19] Low EL, Menon U, JonesA, et al. Ovarian cancer symptom awareness and anticipated time to help-seeking for symptoms among UK women. J Fam Plann Reprod Health Care. 2013; 39: 163171. PMid:23709609 http://dx.doi.org/10.1136/jfprhc-2 012-100473

[20] American cancer society. Can ovarian cancer be prevented? 2015. www.cancer.org Ovarian Cancer Overview Guide Women with a family history of ovarian might want to find out if they have a family cancer. 2015

[21] Tworoger SS, Fairfield KM, Colditz GA, et al. Association of oral contraceptive use, other contraceptive methods, and infertility with ovarian cancer risk. American Journal of Epidemiology. 2007; 166(8): 894-901. PMid:17656616 http://dx.doi.org/10.1093/aje/k wm157

[22] Rice MS, Murphy MA, Tworoger SS. Tubal ligation, hysterectomy and ovarian cancer: A meta-analysis. Journal of Ovarian Research. 2012; 5(13): 1-16. 